\title{
25 Research Square \\ Factors Influencing Antenatal Care Utilization in the East Akim Municipality of Ghana
}

\section{Richard Dickson Amoako}

Institute of Development Studies, University of Antwerp

Innocent Kwau Doku

University of Ghana Noguchi Memorial Institute for Medical Research

Juliana Yartey Enos ( $\nabla$ efuaenos@gmail.com )

University of Ghana Noguchi Memorial Institute for Medical Research https://orcid.org/0000-00033055-3477

\section{Research}

Keywords: Antenatal Care, Unintended Pregnancy, Equity, Maternal Health, Health Services Utilization

Posted Date: July 16th, 2020

DOI: https://doi.org/10.21203/rs.3.rs-42839/v1

License: @ (i) This work is licensed under a Creative Commons Attribution 4.0 International License. Read Full License 


\section{Abstract \\ Background}

Maternal and neonatal mortality rates continue to be high in sub-Saharan African countries, including Ghana. Timely and regular antenatal care (ANC) during pregnancy are essential for early identification and management of potential risk factors associated with poor pregnancy outcomes. The purpose of this study was to investigate the uptake of ANC services in the East Akim Municipality of Ghana and identify factors influencing ANC utilization.

\section{Methods}

A cross-sectional study which employed stratified sampling methodology to select 310 women in their reproductive ages (15-49 years) in East Akim Municipality was conducted. A structured questionnaire was used to examine the determinants of ANC utilization among respondents. Data was managed using Microsoft Excel 2016 and analysed using Stata version 14. Descriptive, bivariate and multivariable logistic regression analyses were performed.

\section{Results}

ANC attendance, at least once during pregnancy, was almost universal (98.4\%) with $83.5 \%$ making $4+$ visits. However, only $58 \%$ of respondents made early ANC visits in the first trimester and $61 \%$ attended all regularly scheduled visits. Employment status, distance to health facility and pregnancy intention were significantly associated with regular ANC attendance. Self-employed women were 2.4 times more likely to attend ANC regularly (AOR: $2.42,95 \% \mathrm{Cl}: 1.20-4.88$ ) than the unemployed; those who lived $<5 \mathrm{~km}$ to a health facility were 3.2 times more likely to attend ANC regularly than those who lived > $10 \mathrm{~km}$ (AOR: 3.24 , $95 \% \mathrm{Cl}: 1.20,8.72)$; and women with intended pregnancies were 2.5 times more likely to attend all ANC scheduled visits than those with unintended pregnancies (AOR: $2.46,95 \% \mathrm{Cl}: 1.32,4.57$ ).

\section{Conclusion}

Although ANC utilization in East Akim Municipality is high, socioeconomically disadvantaged women who were unemployed; lived more than $10 \mathrm{~km}$ from a health facility; and those with unintended pregnancies did not attend ANC early and regularly. Interventions to ensure equitable access to quality reproductive health services at the community level for all women, irrespective of their socioeconomic background, is needed to improve timely and regular ANC utilization. These include strengthening of community-based health centers, provision of ANC through outreach services to poor women in remote, hard-to-reach locations and improvements in the socioeconomic conditions in which people live. 


\section{Introduction}

High maternal and neonatal mortality rates in developing countries remain major public health concerns, despite significant global reduction efforts, which began with the Safe Motherhood Initiative in 1987 (1). The United Nations Millennium Development Goal (MDG) 5, which aimed at reducing maternal mortality by three-quarters of the 1990 rates and achieving universal access to reproductive health services by 2015 , did not achieve the set targets (2). In 2017, approximately 810 women worldwide died daily from pregnancy-related complications (3). Ninety-four percent (94\%) of these deaths occurred in developing countries and were attributed to hemorrhage, puerperal sepsis, obstructed labour, hypertensive disorders and unsafe abortions $(3,4)$. In Ghana, the Maternal Health Survey of 2017 estimated the maternal mortality ratio at 310 deaths per 100,000 live births, which is far from the SDG 3.1 target of 70 per 100,000 live births expected to be achieved by 2030 (13). Women's vulnerability to such adverse health outcomes could be minimized through appropriate maternal healthcare, especially during pregnancy and childbirth. However, due to limited access to healthcare and poor health seeking behaviors, these complications are often not promptly detected and managed, resulting in poor pregnancy outcomes $(5$, $6)$.

Antenatal care (ANC) during pregnancy provides opportunities for preventing and treating obstetric complications, preparing for emergencies, providing family planning services, and attending to the nutritional, social and emotional needs of the woman and the foetus. (7-10). ANC services create the opportunity for service providers to establish contact with the pregnant woman, to identify and manage current and potential risks and problems during pregnancy, and to establish a delivery plan based on her needs, resources and circumstances (10-12). Women can access ANC either by visiting a health facility where interventions such as tetanus toxoid immunization, deworming, iron and folic acid supplementation and counseling on maternal health are available; or from health workers during their community visits $(13,14)$.

WHO recommends at least four ANC visits during pregnancy. The first visit is to be made within the first trimester of pregnancy (i.e. gestational age of less than 12 weeks), followed by a minimum of three subsequent visits until delivery. The first trimester visit (early antenatal care), which is essential to identify and evaluate the risk factors usually present before pregnancy $(10,15)$, is often poorly patronized $(16)$. Although global coverage of early antenatal care has improved in the last 2 decades, increasing from about $40.9 \%$ in 1990 to $58.6 \%$ in 2013 , substantial inequalities between regions and income groups remain. In 2013 , less than half (48.1\%) of all women in developing countries received early antenatal care in the first trimester compared to $84.8 \%$ in developed regions; and $24.0 \%$ in low income countries compared to $81.9 \%$ in high income countries (16). Addressing inequities in early ANC uptake will require an understanding of the contextual factors that influence ANC utilization, including service availability and access. Even in settings where ANC services are available, uptake by pregnant women is often far from universal (17). Although evidence from several low- and middle-income countries indicate a considerable increase in ANC attendance in recent times, the percentage of women receiving all routine 
ANC interventions remains low, ranging from $10 \%$ in Jordan to about $50 \%$ in Nigeria, Nepal, Colombia and Haiti, and interventions provided in the care package may be sub-optimal (18).

Timely and regular ANC visits are expected to provide opportunities for delivering interventions to improve pregnancy outcomes and impact maternal and newborn health outcomes $(10,19)$. Thus, understanding the factors that influence ANC utilization in various settings is critical for developing appropriate interventions for increasing uptake, assuring equitable access, improving timeliness and ensuring safe pregnancies and outcomes. This study aimed at investigating the extent of antenatal care utilization in the East Akim Municipality of Ghana and the factors that influence timely and regular ANC visits during pregnancy.

\section{Methods}

The study was conducted in the East Akim Municipality, which is one of the twenty-six administrative districts in the Eastern region of Ghana with Kyebi as its municipal capital. East Akim Municipal Assembly has a population of 167,896 of which $51.3 \%$ are females, according to the 2010 Population and Housing Census (20). Nearly $40 \%$ of the population is rural and predominantly engaged in agriculture, fishing, forestry, crafts and trading. The municipality has two hospitals, four health centres, twelve CHPS compounds and two maternity homes which provide maternal health services.

\section{Data Collection Methods and Tools}

A structured questionnaire, guided by the research questions and objectives of this study was developed and administered by trained Field Assistants. The questionnaire documented the respondents' demographic characteristics and utilization of ANC services during pregnancy. Pre-testing of the questionnaire was done with 10 women from Fanteakwa, a nearby district in the East Akim municipality with similar socio-demographic characteristics as the target population. Completed questionnaires were checked for completeness. Other data obtained in the municipality included health system characteristics such as the distribution of health facilities and cost of maternity services that influenced health services utilization.

The study sample size was determined using an estimated population of women in their reproductive ages of about 41,601 with a 5\% margin of error. Using Epi info sample size calculator, the estimated sample size was 310 assuming a non-response rate of $8 \%$. Stratified Sampling technique was used to select the required sample for the study. The communities within the East Akim Municipality were stratified into two groups; urban and rural strata with nine (9) and eleven (11) major communities respectively. A simple random sampling methodology was used to select a total of four communities from both rural and urban strata.. Three hundred and ten respondents (310) respondents were drawn from the 4 randomly selected communities according to their population proportion. Women in their reproductive age (15-49 years) residing in the selected communities who had experienced pregnancy and child birth in the last two years prior to the study were considered eligible for the study. Those who 
consented to participate during a household survey were enroled in the study as participants, and interviewed using a structured questionnaire. All households were visited until the required number of respondents for each community was achieved.

\section{Ethical Consideration}

Ethical approval was obtained from the Ethical Review Board of the Ghana Health Service through the East Akim Health Directorate. Informed consent was read to each participant and approval obtained before data collection. Respondents were also assured of confidentiality and anonymity was assured by using assigned codes instead of respondents names on the questionnaires. Study participants were informed of their right to opt out of the study at any time.

\section{Data Analysis}

The data collected was managed using Microsoft Excel 2016 and analyzed using STATA statistical software version 14. Univariate analysis of socio-demographic and other variables was performed for descriptive purposes. Bivariate analysis was used to investigate the association between women's sociodemographic characteristics, individual and health system factors and regular antenatal visits at $95 \%$ Confidence Interval and statistical significance level of 5\%. Multivariate logistic regression modeling was employed to determine the predictors of regular ANC attendance during pregnancy.

\section{Results}

Three hundred and ten (310) participants completed questionnaires yielding a response rate of $100 \%$. Analysis was therefore done on all 310 completed questionnaires.

\section{Demographic Characteristics of Study Participants}

The demographic characteristics of the respondents are presented in Table 1. The average age of respondents was 27 ( \pm 6.57 ) years, ranging from 16 to 42 years. A high proportion of the respondents (88.4\%) had formal education with $11.6 \%$ having no formal education. More than half of the respondents (50.6\%) had attained Middle or Junior High School (JHS) education, 24.2\% had primary education and $5.2 \%$ had tertiary or higher education. Despite the relatively high number of women with formal education, only $7.1 \%$ were formally employed, $47.1 \%$ were informally employed and $45.8 \%$ were unemployed. More than a third of the respondents $(41 \%)$ had no stable income, with very few (3\%) earning a relatively high annual income above Ghc1000 ( USD 250). Respondents were predominantly rural residents (63.2\%) with $36.8 \%$ residing in urban areas. With regards to ethnicity, more than half of the respondents (50.3\%) were from the Akan ethnic group, 20\% were Ewes, 19\% were Krobos and $10.7 \%$ were from other ethnic groups. Most of the respondents were Christian (93.6\%). About 35.4\% of the respondents were married, $22.3 \%$ were single mothers and $42.3 \%$ were cohabiting, that is, living with a partner without formal marriage. Almost $60 \%$ of the respondents had up to two births and $40.3 \%$ had three or more births. 
Table 1

Demographic Characteristics of Respondents $(N=310)$

\begin{tabular}{|c|c|c|}
\hline Characteristics & $\begin{array}{l}\text { Frequency } \\
(n=310)\end{array}$ & $\begin{array}{l}\text { Percentage } \\
(\%)\end{array}$ \\
\hline \multicolumn{3}{|l|}{ Age (Years) } \\
\hline $16-22$ & 95 & 30.7 \\
\hline $23-28$ & 115 & 37.1 \\
\hline $29-34$ & 54 & 17.4 \\
\hline $35-43$ & 46 & 14.8 \\
\hline \multicolumn{3}{|l|}{ Parity } \\
\hline 1-2 children & 185 & 59.7 \\
\hline 3-8 children & 125 & 40.3 \\
\hline \multicolumn{3}{|l|}{ Education } \\
\hline No Formal Education & 36 & 11.6 \\
\hline Primary & 75 & 24.2 \\
\hline Middle/JSS/JHS & 157 & 50.6 \\
\hline SSS/SHS/Vocational & 26 & 8.4 \\
\hline Tertiary/Polytechnic & 16 & 5.2 \\
\hline \multicolumn{3}{|l|}{ Ethnicity } \\
\hline Akan & 156 & 50.3 \\
\hline Ewe & 62 & 20.0 \\
\hline Krobo & 59 & 19.0 \\
\hline Other & 33 & 10.7 \\
\hline \multicolumn{3}{|l|}{ Religion } \\
\hline Christian & 290 & 93.6 \\
\hline Muslim & 15 & 4.8 \\
\hline No Religion & 5 & 1.6 \\
\hline \multicolumn{3}{|l|}{ Marital Status } \\
\hline Married & 110 & 35.5 \\
\hline Co-habiting & 131 & 42.3 \\
\hline
\end{tabular}




\begin{tabular}{|lll|}
\hline Characteristics & $\begin{array}{l}\text { Frequency } \\
(\mathbf{n = 3 1 0})\end{array}$ & $\begin{array}{l}\text { Percentage } \\
\text { (\%) }\end{array}$ \\
\hline Single & 69 & 22.2 \\
\hline Employment Status & & \\
\hline Formal/Salary workers & 22 & 7.1 \\
\hline Informal/self-employed & 146 & 47.1 \\
\hline Unemployed & 142 & 45.8 \\
Income Status & 9 & 3.0 \\
High Income (> GHC 1000 ( US\$250)) & 174 & 56.0 \\
Low-to-medium (<GHC1000 ( US\$250)) & 127 & 41.0 \\
No income & & \\
\hline Residence & & \\
\hline Rural & 196 & 63.2 \\
\hline Urban & 114 & 36.8 \\
\hline Characteristics AsSOCiated With the USe Of
\end{tabular}

Table 2 presents data on some individual respondent characteristics associated with the use of maternity services. Most (69\%) of the respondents had a previous childbirth prior to their current child or the last birth at the time of the study with the remaining $31 \%$ having no previous childbirth experience. Also, a high proportion of pregnancies $(63.2 \%)$ were unintended with only $36.8 \%$ being intended. Less than a third $(28.1 \%)$ of respondents had a history of pregnancy complications, with $18.7 \%$ of the women reporting difficulties with their last childbirth. The most common delivery mode experienced by the mothers was vaginal (85.8\%), with about $14 \%$ having either emergency or planned caesarean delivery.

Decision-making power among women in this community was low with almost half of the respondents (46.1\%) having low or no decision-making power concerning their pregnancy and childbirth. However, family support for women during pregnancy and childbirth was rather high at $78.7 \%$. Only $21.3 \%$ of the respondents indicated that they did not receive any support from their families during their last pregnancy. Supportive family members include partners, parents and in-laws.

More than half of the respondents (53.9\%) indicated that they obtained information about pregnancy and childbirth-related issues from the media. Among the types of media mentioned were television by $50 \%$ of the respondents, radio $(29 \%), 12 \%$ indicated they received information from both radio and television and $9 \%$ mentioned internet or social media. 
Table 2

Individual Characteristics Associated with the Use of Maternity Services

\begin{tabular}{|c|c|c|}
\hline Individual Characteristics & $\begin{array}{l}\text { Frequency } \\
\text { (n) }\end{array}$ & $\begin{array}{l}\text { Percentage } \\
\text { (\%) }\end{array}$ \\
\hline \multicolumn{3}{|l|}{ Previous childbirth } \\
\hline Yes & 214 & 69.0 \\
\hline No & 96 & 31.0 \\
\hline \multicolumn{3}{|l|}{ Mode of Delivery } \\
\hline Vaginal & 266 & 85.8 \\
\hline Emergency Caesarean & 38 & 12.3 \\
\hline Planned Cesarean & 6 & 1.9 \\
\hline \multicolumn{3}{|l|}{ Intended Pregnancy } \\
\hline Yes & 114 & 36.8 \\
\hline No & 196 & 63.2 \\
\hline \multicolumn{3}{|c|}{ Complications with Index Pregnancy } \\
\hline Yes & 87 & 28.1 \\
\hline No & 223 & 71.9 \\
\hline \multicolumn{3}{|c|}{ Difficulties with Previous Pregnancy } \\
\hline Yes & 58 & 18.7 \\
\hline No & 252 & 81.3 \\
\hline \multicolumn{3}{|l|}{ Family Structure } \\
\hline Nuclear Family & 205 & 66.1 \\
\hline Extended Family & 105 & 33.9 \\
\hline \multicolumn{3}{|c|}{ Availability of Family Support } \\
\hline Yes & 244 & 78.7 \\
\hline No & 66 & 21.3 \\
\hline \multicolumn{3}{|c|}{ Pregnancy-related Decision-making Power } \\
\hline High & 63 & 20.3 \\
\hline Medium & 104 & 33.6 \\
\hline Low & 143 & 46.1 \\
\hline
\end{tabular}




\begin{tabular}{l|l|l|}
\hline Individual Characteristics & $\begin{array}{l}\text { Frequency } \\
\text { (n) }\end{array}$ & $\begin{array}{l}\text { Percentage } \\
(\%)\end{array}$ \\
\hline Health Status during Pregnancy & & \\
\hline Fair & 33 & 10.6 \\
\hline Good & 172 & 55.5 \\
\hline Very Good & 105 & 33.9 \\
\hline Access to Pregnancy-related Information through media & & \\
\hline Yes & 167 & 53.9 \\
\hline No & 143 & 46.1 \\
\hline Media for Accessing Pregnancy-related Information & & \\
\hline TV only & 155 & 50.0 \\
\hline Radio Only & 90 & 29.0 \\
\hline Both TV and Radio & 37 & 12.0 \\
\hline Social Media/internet/phone & 28 & 9.0 \\
\hline
\end{tabular}

Table 3 shows the health system factors associated with the use of maternity services. Majority of the mothers (88.7\%) admitted to the availability of maternity services within their community. More than half of the respondents (56.4\%) lived within 5 to 10 kilometers to the nearest health facility and $34.2 \%$ lived less than 5 kilometers to the closest health facility. Only $9.4 \%$ of the respondents lived more than 10 kilometers from the nearest health facility.

Maternal health care was largely financed through health insurance (83.5\%), which was corroborated by evidence of a high proportion of respondents $(95.8 \%)$ having an active health insurance card. Other means of payment for maternal health care included out-of-pocket (12.6\%) and family support (3.9\%). About $12 \%$ of respondents rated the cost of maternity services as high; $27.4 \%$ as moderate and $9 \%$ as low. More than half of the mothers (51.6\%) could not rate the cost of maternity care because they believed they did not incur any extra cost above the insurance coverage. Most of the respondents described the attitude of health workers as excellent (33.8\%) or very good $(39.7 \%)$, with $15.8 \%$ describing it as good, and $10.7 \%$ describing it as fair or poor. 
Table 3

Health System Characteristics Associated with the Use of Maternity Services

\begin{tabular}{|c|c|c|}
\hline Health System Characteristics & $\begin{array}{l}\text { Frequency } \\
(n=310)\end{array}$ & $\begin{array}{l}\text { Percentage } \\
\text { (\%) }\end{array}$ \\
\hline \multicolumn{3}{|c|}{ Maternity Services available in Community } \\
\hline Yes & 275 & 88.7 \\
\hline No & 35 & 11.3 \\
\hline \multicolumn{3}{|l|}{ Distance to the Nearest Facility } \\
\hline Less than 5 kilometers(close) & 106 & 34.2 \\
\hline 5 to 10 kilometers (Far) & 175 & 56.4 \\
\hline More than 10 kilometers (Very Far) & 29 & 9.4 \\
\hline \multicolumn{3}{|l|}{ Attitude of Health Workers } \\
\hline Excellent & 105 & 33.8 \\
\hline Very Good & 123 & 39.7 \\
\hline Good & 49 & 15.8 \\
\hline Fair & 17 & 5.5 \\
\hline Poor & 16 & 5.2 \\
\hline \multicolumn{3}{|l|}{ Having Active Health Insurance } \\
\hline Yes & 297 & 95.8 \\
\hline No & 13 & 4.2 \\
\hline \multicolumn{3}{|l|}{ Sources of Healthcare Financing } \\
\hline Health Insurance & 259 & 83.5 \\
\hline Out of pocket & 39 & 12.6 \\
\hline Family Support & 12 & 3.9 \\
\hline \multicolumn{3}{|l|}{ Cost of Maternity Services } \\
\hline High & 37 & 12.0 \\
\hline Moderate & 85 & 27.4 \\
\hline Low & 28 & 9.0 \\
\hline Don't Know & 160 & 51.6 \\
\hline
\end{tabular}




\section{Antenatal Care Attendance Among Respondents}

Antenatal care utilization in East Akim was found to be high with $98.4 \%$ of respondents who had a birth in the two years preceding the study having at least one ANC visit during pregnancy (Table 4). Majority of women (83.5\%) had four or more visits as recommended by WHO and only $1.6 \%$ did not make any ANC visit during their pregnancy. However, among the women who attended ANC, 61\% made regular ANC visits without missing an appointment. The remaining $39 \%$ missed at least one appointment. The average number of ANC visits by respondents was $6 \pm 2.3$ with a range of 1 to 11 visits. ANC was largely accessed from government hospital or clinics (91.9\%). Others accessed their care from health centers $(5.8 \%)$ with a small proportion $(0.7 \%)$ accessing services from private facilities. Some respondents $(27.7 \%)$ reported having difficulty reaching ANC services. Among those respondents, reasons for such difficulties include long distance $(24.9 \%)$, cost $(25.6 \%)$ and poor physical and environmental conditions of the facility $(29.1 \%)$ respectively. Other reasons indicated were lack of support from family $(15.1 \%)$ and time constraints (2.3\%), especially for working mothers (Table 4 ). 
Table 4

Antenatal Care Attendance Among Respondents ( $N=310)$

\begin{tabular}{|c|c|c|}
\hline Variables & $\begin{array}{l}\text { Frequency } \\
(n=310)\end{array}$ & $\begin{array}{l}\text { Percentage } \\
\text { (\%) }\end{array}$ \\
\hline \multicolumn{3}{|l|}{ At least one ANC visit } \\
\hline Yes & 305 & 98.4 \\
\hline No & 5 & 1.6 \\
\hline Number of ANC visits & 5 & 1.6 \\
\hline \multicolumn{3}{|l|}{ None } \\
\hline $1-3$ & 51 & 16.5 \\
\hline $4+$ & 259 & 83.5 \\
\hline Average Number of ANC visits & 6 & $\mathrm{SD} \pm 2.3$ \\
\hline Regular ANC attendance & 189 & 61.0 \\
\hline Yes & 121 & 39.0 \\
\hline \multicolumn{3}{|l|}{ No } \\
\hline \multicolumn{3}{|l|}{ ANC Provider } \\
\hline Midwife & 100 & 32.3 \\
\hline Nurse & 190 & 61.3 \\
\hline Doctor & 15 & 4.8 \\
\hline None & 5 & 1.6 \\
\hline \multicolumn{3}{|l|}{ Place of receiving ANC } \\
\hline Hospital/Clinic. & 285 & 91.9 \\
\hline Health Center & 18 & 5.8 \\
\hline Private facility & 2 & 0.7 \\
\hline None & 5 & 1.6 \\
\hline \multicolumn{3}{|l|}{ Having difficulties accessing ANC } \\
\hline Yes & 86 & 27.7 \\
\hline No & 224 & 72.3 \\
\hline \multicolumn{3}{|c|}{ Type / reason for difficulties $(n=86)$} \\
\hline Long distance & 24 & 27.9 \\
\hline
\end{tabular}




\begin{tabular}{|c|c|c|}
\hline Variables & $\begin{array}{l}\text { Frequency } \\
(n=310)\end{array}$ & $\begin{array}{l}\text { Percentage } \\
(\%)\end{array}$ \\
\hline Cost & 22 & 25.6 \\
\hline Lack of family support & 13 & 15.1 \\
\hline Poor physical condition (environment) & 25 & 29.1 \\
\hline Lack of time & 2 & 2.3 \\
\hline
\end{tabular}

Table 5 shows the timing and frequency of ANC visits among respondents. Early ANC visits, occuring in the first trimester of pregnancy was relatively high among the respondents $(58.0 \%)$ ranging from $49.5 \%$ among 16-22 year olds to $72.2 \%$ among 29-34 year olds. Thus, older mothers seem to access ANC earlier than younger mothers. A higher proportion of mothers in formal employment (72.7\%) and urban residence (61.4\%) also made early ANC visits compared with $54.7 \%$ among the unemployed and $56.0 \%$ among rural residents. A high proportion of mothers with secondary level or higher education $(71.4 \%)$ also accessed ANC in the first trimester. ANC visits were classified as either adequate - at least four visits $(4+)$ or inadequate - less than four visits (<4). About $83.5 \%$ of respondents in this study had at least 4 ANC visits. A high proportion of women in both urban $(90.4 \%)$ and rural $(79.6 \%)$ areas had at least 4 visits as compared to $9.6 \%$ of urban and $20.4 \%$ of rural residents who had less than four visits. Almost all women in formal employment (95.4\%) had at least 4 ANC visits. 
Table 5

Timing and Frequency of ANC Visits among Respondents

\begin{tabular}{|c|c|c|c|c|}
\hline \multirow{3}{*}{$\begin{array}{l}\text { Characteristics } \\
\text { of Respondents }\end{array}$} & \multicolumn{2}{|c|}{ ANC Timing $(\mathrm{N}=305)$} & \multicolumn{2}{|c|}{ No. of ANC Visits $(N=310$} \\
\hline & Early & Late & $4+$ visits & $<4$ visits \\
\hline & $(\%)$ & $(\%)$ & $(\%)$ & (\%) \\
\hline Age Group & $45(49.5)$ & $46(50.5)$ & $72(75.8)$ & $23(24.2)$ \\
\hline $16-22$ & $66(57.9)$ & $48(42.1)$ & $96(83.5)$ & 19 (16.5) \\
\hline $23-28$ & $39(72.2)$ & $15(27.7)$ & $52(96.3)$ & $2(3.7)$ \\
\hline $29-34$ & $27(58.7)$ & $19(41.3)$ & $39(84.8)$ & $7(15.2)$ \\
\hline \multicolumn{5}{|l|}{$35-43$} \\
\hline Residence & $107(56.0)$ & $84(44.0)$ & $156(79.6)$ & $40(20.4)$ \\
\hline Rural & $70(61.4)$ & $44(38.6)$ & $103(90.4)$ & $11(9.6)$ \\
\hline \multicolumn{5}{|l|}{ Urban } \\
\hline Education & $21(60.0)$ & $14(40.0)$ & $28(77.8)$ & $8(22.2)$ \\
\hline None & $126(55.3)$ & $102(44.7)$ & $191(82.3)$ & $41(17.7)$ \\
\hline Primary to JHS & $30(71.4)$ & $12(28.6)$ & $40(95.2)$ & $2(4.8)$ \\
\hline \multicolumn{5}{|l|}{ Secondary of Higher } \\
\hline Parity & $106(57.6)$ & $78(42.4)$ & $154(83.2)$ & $31(16.8)$ \\
\hline $1-2$ & $71(58.7)$ & $50(41.3)$ & $105(84.0)$ & $20(16.8)$ \\
\hline \multicolumn{5}{|l|}{$>2$} \\
\hline Employment Status & $16(72.7)$ & $6(27.3)$ & $21(95.4)$ & $1(4.6)$ \\
\hline Formal/salary worker & $86(58.9)$ & $60(41.1)$ & $126(86.3)$ & $20(13.7)$ \\
\hline Informal/self employed & $75(54.7)$ & $62(45.3)$ & 112 (78.9) & 30 (21.1) \\
\hline Unemployed & & & & \\
\hline
\end{tabular}

\section{Bivariate Analysis of Demographic Factors Associated with Regular ANC Attendance}

Table 6 shows the demographic factors associated with the regular use of antenatal services among respondents. Among the demographic factors, age of mothers, educational levels and residence were found to be significantly associated with regular antenatal visits ( $p$-values $<0.001,0.004$ and $<0.001$ respectively). Women's employment status and marital status were also found to be significantly 
associated with regular antenatal visits with $p$-values $<0.001$ and 0.007 respectively. Parity and ethnicity were not significantly associated with regular ANC attendance. 
Table 6

Bivariate Analysis of Demographic Factors Associated with Regular ANC Attendance

\begin{tabular}{|c|c|c|c|}
\hline Variables & $\begin{array}{l}\text { Regular ANC } \\
\text { Yes No } \\
\text { n (\%) n (\%) }\end{array}$ & Attendance & P-value \\
\hline $\begin{array}{l}\text { Age } \\
\leq 28 \text { years } \\
\geq 29 \text { years }\end{array}$ & $\begin{array}{l}113(59.8) \\
76(40.2)\end{array}$ & $\begin{array}{l}97(80.2) \\
24(19.8)\end{array}$ & $0.001 *$ \\
\hline $\begin{array}{l}\text { Education } \\
\text { None } \\
\text { Primary/JSS } \\
\text { Secondary or High }\end{array}$ & $\begin{array}{l}23(12.2) \\
131(69.3) \\
35(18.5)\end{array}$ & $\begin{array}{l}13(10.7) \\
101(83.5) \\
7(5.8)\end{array}$ & $0.004^{\star}$ \\
\hline $\begin{array}{l}\text { Religion } \\
\text { Christian } \\
\text { Muslim } \\
\text { None }\end{array}$ & $\begin{array}{l}177(93.7) \\
11(5.8) \\
1(0.5)\end{array}$ & $\begin{array}{l}113(93.4) \\
4(3.3) \\
4(3.3)\end{array}$ & 0.107 \\
\hline $\begin{array}{l}\text { Residence } \\
\text { Rural } \\
\text { Urban }\end{array}$ & $\begin{array}{l}105(55.6) \\
84(44.4)\end{array}$ & $\begin{array}{l}91(75.2) \\
30(24.8)\end{array}$ & $<0.001^{*}$ \\
\hline $\begin{array}{l}\text { Employment Status } \\
\text { Formal/Salary worker } \\
\text { Informal/self-employed } \\
\text { Unemployed }\end{array}$ & $\begin{array}{l}18(9.5) \\
108(57.2) \\
63(33.3)\end{array}$ & $\begin{array}{l}4(3.3) \\
38(31.4) \\
79(65.3)\end{array}$ & $<0.001^{*}$ \\
\hline Ethnicity & 98 (51.9) & $58(47.9)$ & 0.284 \\
\hline Akan & 35 (18.5) & $27(22.3)$ & \\
\hline Ewe & $32(16.9)$ & $27(22.3)$ & \\
\hline $\begin{array}{l}\text { Krobo } \\
\text { Other }\end{array}$ & $24(12.7)$ & $9(7.5)$ & \\
\hline
\end{tabular}




\begin{tabular}{|llll|}
\hline Variables & $\begin{array}{l}\text { Regular ANC Attendance } \\
\text { Yes No }\end{array}$ & P-value \\
& $\mathbf{n}(\%) \mathbf{n}(\%)$ & \\
\hline Marital Status & $76(40.2)$ & $55(45.5)$ & $0.007^{\star}$ \\
Cohabitation & $79(41.8)$ & $31(25.6)$ & \\
Married & $34(18.0)$ & $35(28.9)$ & \\
Single & & & \\
Parity & $109(57.7)$ & $76(62.8)$ & 0.368 \\
$1-2$ & $80(42.3)$ & $45(37.2)$ & \\
$>2$ & & & \\
\hline
\end{tabular}

*=p-value < 0.05: measure is significant; $\mathrm{n}$ represents frequencies and \%: percentages

\section{Bivariate Analysis of Individual and Health System Factors Associated with Regular ANC Attendance}

Table 7 shows the results of bivariate analysis of individual and health system factors associated with the regular use of ANC services among respondents. Individual factors such as income status, pregnancy intention and decision-making power were found to be significantly associated with regular ANC visits. (pvalue $<0.05$ ). Interestingly, health status during pregnancy and having an active health insurance were not significantly associated with regular ANC visits. Health system factors such as the availability of maternity services in the community and distance to the nearest health facility were also found to be significantly associated with regular ANC visits ( $p$-value $<0.050)$. 
Table 7

Bivariate Analysis of Individual and Health System Factors Associated with Regular ANC Attendance

\begin{tabular}{|c|c|c|c|}
\hline Individual and Health System Factors & $\begin{array}{l}\text { Regular AN } \\
\text { Yes No } \\
\text { n (\%) n (\%) }\end{array}$ & Attendance & P-value \\
\hline Health Status During Pregnancy & $20(10.6)$ & $13(10.8)$ & 0.321 \\
\hline Fair & $99(52.4)$ & $73(60.3)$ & \\
\hline Good & $70(37.0)$ & $35(28.9)$ & \\
\hline \multicolumn{4}{|l|}{ Very Good } \\
\hline Decision-making Power & $43(22.7)$ & $20(16.5)$ & $0.017^{*}$ \\
\hline High & 75 (39.7) & $68(56.2)$ & \\
\hline Low & $71(37.6)$ & $33(27.3)$ & \\
\hline \multicolumn{4}{|l|}{ Medium } \\
\hline Income Status & $30(15.9)$ & $12(9.9)$ & $<0.001^{*}$ \\
\hline High & $99(52.4)$ & $41(33.9)$ & \\
\hline Low to Medium & $60(31.7)$ & $68(56.2)$ & \\
\hline \multicolumn{4}{|l|}{ No Income } \\
\hline Intended Pregnancy & $101(53.4)$ & $95(78.5)$ & $<0.001^{*}$ \\
\hline No & $88(46.6)$ & $26(21.5)$ & \\
\hline \multicolumn{4}{|l|}{ Yes } \\
\hline Distance to Health Facility & $64(33.9)$ & $42(34.7)$ & $<0.001^{*}$ \\
\hline Less than 5 kilometers & $117(61.9)$ & $58(47.9)$ & $0.050^{\star}$ \\
\hline 5 to 10 kilometers & $8(4.2)$ & $21(17.4)$ & \\
\hline More than & $16(8.5)$ & $19(15.7)$ & \\
\hline Availability of Maternity Services & $173(91.5)$ & $102(84.3)$ & \\
\hline \multicolumn{4}{|l|}{ No } \\
\hline Yes & & & \\
\hline
\end{tabular}

Predictors of Regular ANC Attendance 
Table 8 compares unadjusted and adjusted odds ratios of variables which were found to be significantly associated with regular ANC attendance in the bivariate analysis, to determine the likelihood of a woman having a regular ANC visit. After adjusting for confounders, employment status was found to be a significant predictor of regular ANC utilization. Women who were engaged in informal employment were about 2.4 times more likely to have regular ANC visits compared to the unemployed (AOR:2.42, 95\%Cl: 1.204-4.488). Also, women in formal employment were almost two times more likely to fulfil all their antenatal appointments than those not employed (AOR: 1.94, 95\%Cl: 0.298-12.615). However, this association was not statistically significant ( $p$-value, 0.488$)$.

Distance to the health facility was found to be a significant predictor of regular ANC utilization after adjusting for age, education, marital status and residence. Compared to those who lived more than 10 kilometers to a health facility, women who lived less than 5 kilometers were 3.2 times more likely to have regular ANC attendance (AOR :3.24, 95\% Cl:1.20-8.72). Pregnancy intention was also significantly associated with regular ANC visits (AOR: $2.46,95 \% \mathrm{Cl}: 1.32-4.57$. Thus, mothers whose pregnancies were intended were about 2.5 times more likely to have regular ANC visits compared to those whose pregnancies were unintended. 
Table 8

Multivariate Logistic Regression of Variables Associated with Regular ANC Attendance

\begin{tabular}{|c|c|c|c|c|}
\hline Variables & P-value & OR (95\%) & P-Value & AOR $(95 \% \mathrm{Cl})$ \\
\hline Age & Ref & 1 & Ref & 1 \\
\hline 28 and below & 0.0002 & $2.72(1.57,4.70)$ & 0.162 & $1.64(0.82,3.27)$ \\
\hline \multicolumn{5}{|l|}{29 and above } \\
\hline Education & Ref & 1 & Ref & 1 \\
\hline None & 0.4028 & $0.73(0.35,1.521)$ & 0.987 & $1.0(0.44,2.37)$ \\
\hline Primary/JHS & 0.0514 & $2.83(0.95,8.43)$ & 0.237 & $2.48(0.55,11.14)$ \\
\hline \multicolumn{5}{|l|}{ Secondary/ Higher } \\
\hline Residence & Ref & 1 & Ref & 1 \\
\hline Rural & 0.0005 & $2.42(1.45,4.06$ & 0.126 & $1.62(0.87,3.01)$ \\
\hline \multicolumn{5}{|l|}{ Urban } \\
\hline Employment Status & Ref & 1 & Ref & 1 \\
\hline Unemployed & 0.001 & $3.56(2.12,6.00)$ & 0.013 & $2.42(1.20,4.88)^{\star}$ \\
\hline Informal/self-employ & 0.0011 & $5.64(1.74,18.28)$ & 0.488 & $1.94(0.30,12.62)$ \\
\hline \multicolumn{5}{|l|}{ Formal work } \\
\hline Marital Status & Ref & 1 & Ref & 1 \\
\hline Single & 0.2388 & $1.42(0.79,2.56)$ & 0.864 & $0.94(0.46,1.93)$ \\
\hline Cohabiting & 0.0024 & & 0.682 & $0.83(0.36,1.95)$ \\
\hline \multicolumn{5}{|l|}{ Married } \\
\hline Distance to Facility & Ref & 1 & Ref & 1 \\
\hline More than $10 \mathrm{~km}$ & 0.0001 & $5.29(2.13,13.18)$ & 0.074 & $2.56(0.91,7.17)$ \\
\hline 5 to 10 kilometers & 0.0018 & $4.00(1.56,10.25)$ & 0.020 & $3.24(1.20,8.72)^{\star}$ \\
\hline \multicolumn{5}{|l|}{ Less than 5 kilometers } \\
\hline Available Maternity Service & Ref & 1 & Ref & 1 \\
\hline No & 0.0499 & $2.01(0.99,4.11)$ & 0.125 & $2.04(0.82,5.06)$ \\
\hline Yes & & & & \\
\hline
\end{tabular}




\begin{tabular}{|lllll|}
\hline Variables & P-value & OR $(95 \%)$ & P-Value & AOR $(95 \% \mathrm{Cl})$ \\
\hline Decision Power & Ref & 1 & Ref & 1 \\
Low & 0.0350 & $1.95(1.04,3.37)$ & 0.841 & $1.084(0.50,2.37)$ \\
High & 0.0127 & $1.95(1.14,3.32)$ & 0.287 & $1.42(0.75,2.69)$ \\
Medium & & & & \\
Income Status & Ref & 1 & Ref & 1 \\
No Income & 0.0058 & $2.83(1.31,6.14)$ & 0.160 & $0.45(0.15,1.37)$ \\
High income & 0.0001 & $2.74(1.63,4.60)$ & 0.790 & $1.10(0.54,2.23)$ \\
Low to medium & & & & \\
\hline Intended Pregnancy & Ref & 1 & Ref & 1 \\
No & $<0.001$ & $3.18(1.86,5.45)$ & 0.005 & $2.46(1.32,4.57)^{\star}$ \\
Yes & & & & \\
\hline
\end{tabular}

Note: OR-Unadjusted odds ratio, AOR-Adjusted odds ratio, Cl-Confidence Interval, a $<0.05$ (significance level)

\section{Discussions}

Despite increasing investments and attention to maternal health globally, maternal and neonatal mortality remains high in most developing countries and has been attributed to the non-utilization of maternal health services (21). Towards universal access to health care, the government of Ghana adopted the Community-based Health Planning and Services (CHPS) programme in 1999 as a national health policy initiative to reduce geographical barriers to healthcare and promote universal access to health services in the country (23). A "free maternal health" policy, which was part of the National Health Insurance ACT (650) introduced in 2003, also aimed at removing financial barriers and improving access to maternal and newborn health care (22). Other initiatives aimed at improving maternal and newborn health outcomes include the training, recruitment and posting of more nurses and midwives to peripheral health facilities, especially in rural communities.

The outcome of this study demonstrates a high level of ANC utilization among women in the East Akim municipality (98.4\%). This finding is aligned with findings of the 2017 Ghana Maternal Health Survey (GMHS, 2017), which reported $98 \%$ of mothers surveyed nationally receiving at least one antenatal care (13). This study also finds that a high proportion of mothers (83.5\%) made the WHO recommended $4+$ ANC visits during pregnancy. This observation also compares well with those by Asundep et al (2014) who reported that $89 \%$ of mothers in the Ashanti region of Ghana access $4+$ ANC visits (24); Yeji et al (2015) who found $86.1 \%$ of pregnant women in three regions of Ghana receiving four or more (4+) ANC visits (26); and the Ghana Demograpic and Health Survey (GDHS, 2014), which put the proportion of 
women receiving $4+$ ANC visits at $87 \%$ (27). These observations demonstrate that Ghana has been successful at expanding coverage of maternal health services, and antenatal care in particular across the country, as indicated in its national strategic plan of 1999, with commensurate policies on Health Insurance to reduce financial barriers to maternal health care $(22,23)$. However, as demonstrated in this study, the GDHS (2014) and the GMHS (2017), although ANC use (at least one visit) is almost universal in Ghana, disparities in attending four or more ANC visits persist across the country and differ by socioeconomic parameters such as age, urban/rural residence, mothers education and income or wealth quintiles. These observations calls for critical interventions to reduce disparities and ensure equity in access and utilization of maternal health servces in Ghana.

\section{Timing of ANC Visits}

With regards to the timing of ANC visits, $58.0 \%$ of the respondents in this study had their initial ANC registration within the first trimester of pregnancy. This observation is comparable to the outcome of the 2017 Maternal Health Survey, where $64 \%$ of mothers had their first ANC visit in the first trimester (13), in line with WHO recommendations (10). Asundep et al (2014) also reported that $61 \%$ of mothers in the Ashanti region of Ghana initated ANC during the first trimester of pregnancy (24). Early timing of first ANC visits is required for early detection, treatment and prevention of conditions that may have adverse consequences for the pregnant woman and her unborn baby. Globally, although coverage of early ANC visits has increased over the past two decades from an estimated $40.9 \%$ in 1990 to $58.5 \%$ in 2013 , coverage in sub-Saharan Africa remained low at $24.9 \%$ in 2013 , increasing from an estimated $17.7 \%$ in 1990 (16). The relatively high patronage of early ANC by about two-thirds of mothers in Ghana and in the study area is impressive and commendable, though opportunities for improvement remain. A study conducted among women in south-eastern Nigeria showed that women usually report late for ANC due to the belief that there are no advantages to early booking, as ANC is perceived primarily as curative rather than preventive (6). Further studies are needed to understand the reasons for late ANC attendance, particularly in sub-Saharan African countries and economically disadvantaged communities. Such information is needed to inform the development of appropriate interventions to encourage and support early ANC attendance.

\section{Determinants of Regular ANC Attendance}

About $61 \%$ of respondents in this study attended all regularly scheduled ANC visits, making an average of six (6) ANC visits per woman. A similar observation has been made in Nigeria where $56.9 \%$ of pregnant women were found to be regular ANC atendees (25). Regular ANC attendance was found to be associated with certain individual, demographic and health system factors such as age, education, urban/rural residence, employment, income, marital status, decision power, availability of maternity services, distance to health facility and pregnancy intention. After adjusting for age, education and employment status of the respondents, distance to the nearest health facility and pregnancy intention were found to be significant predictors of regular ANC attendance. Mothers who lived less than 5 kilometers to a health facility were 3.2 times more likely to fulfil all their regularly scheduled ANC appointments (AOR:3.24, 
95\% Cl:1.20-8.72) than those who lived more than 10 kilometers from the health facility. Jalal \& Shah (2011) also found that rural woman who lived in far and remote areas were less likely to attend ANC than those who did not. An increase in distance implies paying some cost to travel to the source of care as opposed to undertaking self-care at home (28). There is a sense that distance adds an extra burden to the monetary cost of care (29). These concerns were echoed in the present study where $25.6 \%$ of respondents cited cost as a barrier to accessing ANC services.

In this study, women who were unemployed were less ikely to access ANC that those in formal employment and those engaged in informal employment were about 2.4 times more likely to have regular ANC visits compared to the unemployed. Clearly, economic barriers mitigate against regular ANC utilization and reinforce inequities in access to maternal health services. Women in this study whose last pregnancy was intended, were more likely to attend all their ANC appointments (AOR:2.46, 95\%Cl:1.324.57). Pregnancy intention has been documented by several studies to be significantly associated with adequate number of ANC visits $(30,31)$. Other factors reported to be associated with ANC utilization in developing countries include maternal age, parity, education, occupation, place of residence and religion (7).

Public hospitals or clinics were found to be the principal providers of ANC services in the study district (91.9\%), since they are the most common health facilities in the municipality. Private facilities are less common and thus rarely used by women $(0.7 \%)$. About $27.7 \%$ of mothers in this study reported having difficulty reaching ANC services. Among those respondents, more than half cited long distance $(24.9 \%)$ and cost $(25.6 \%)$ as the principal reasons for such difficulties. Women who reside $>10 \mathrm{~km}$ from health facilities complained of muddy and non-motorable roads during the rainy seasons, which is characteristic of deprived, often rural communities in Ghana and other developing countries with inequitable distribution of national resources and infrastructure such as roads. Indeed, poor road conditions have been identified as one of the key factors that prevent women in the Sunamganj district of the Sylhet division of Bangladesh from using healthcare facilities (32). However, health insurance cover was not a significant predictor of regular ANC attendance, probably because almost all women (95.8\%) were enrolled in the government's Free Maternal Health Program and had active health insurance coverage.

\section{Conclusions}

In East Akim Municipality, antenatal care utlilization - at least one visit - is almost universal. A high proportion of mothers attend all scheduled ANC visits and make 4 or more vists during pregnancy, which is likely to ensure that they receive appropriate WHO recommended interventions to ensure good pregnancy outcomes. However, despite the high level of ANC utilization, concerns about equity remain. Socioeconomically disadvantaged mothers who were less educated, with less income and living in remote rural locations failed to honor their regularly scheduled visits during pregnancy. Women who were unemployed, those with unintended pregnancies and those who lived more than $10 \mathrm{~km}$ from a health facility made less frequent use of ANC. The distance between residence and health facility, decision 
making power and the income status of women were found to be significantly associated with regular ANC attendance.

In order to improve the utilization of ANC services, raising the awareness of mothers about the importance of early, timely and regular ANC visits should be a priority. Access to ANC services in both rural and urbal areas can be enhanced by ensuring that community-based health centers and CHPS compounds are appropriately sited and adequately equipped to respond to women's ANC needs. Outreach services by Community Health Workers could also be strengthened to reach women in remote, hard-toreach locations with ANC services. In addition to measures aimed at reinforcing women's autonomy in the society, including economic empowerment and decision-making regarding her fertility, efforts are needed to enhance the quality of information and education given to women of childbearing age regarding their reproductive health. This must include information and access to family planning services which will enable women to make informed reproductive health choices.

Strong political will at the highest level of government is needed to ensure adequate and equitable resourcing to honor the right of mothers to quality reproductive health services that are affordable and accessible to all women irrespective of their socioeconomic, religious, ethnic or educational background. Ensuring equitable access to ANC and other maternal health services, will require improvements in the socioeconomic conditions in which people live, including improvements in road networks to enhance access to health services.

\section{Strengths And Limitations}

This study provides useful baseline data on the prevailing pattern of ANC utilization in the East Akim Municipality of Ghana, which provides a strong basis for strengthening ANC and ensuring equitable access to effective interventions for improving maternal and newborn health outcomes. Experiences from the municipality can also inform programs in other parts of Ghana and the Africa region. The study relied on self-report from the respondents and some of the information provided by the respondents could not be verified, thus raising the potential for information bias. This potential bias was reduced by verifying the authenticity of information provided in the respondents' Antenatal booklet.

\section{Declarations}

\section{Ethics approval and consent to participate}

Ethical approval was obtained from the Review Board of the Ghana Health Service through the East Akim Health Directorate. Informed consent was obtained from participant before data collection. An Ethical Considerations section is included in the Methods section of the Manuscript.

\section{Consent for publication}


The authors consent to the submission of this manuscript for publication.

\section{Availability of data and materials}

The datasets during and/or analysed during the current study available from the corresponding author on reasonable request.

\section{Competing interests}

The authors declare that they have no competing interests.

\section{Funding}

The study was supported by the authors with no external funding.

\section{Authors' contributions}

RDA and JYE designed the study. RDA analyzed the data and drafted the manuscript. IKD and JYE contributed to the data analysis and preparation of the manuscript. All authors worked on revising various drafts of the manuscript and read and approved the final version.

\section{Acknowledgments}

We express our gratitude to the leadership of the Municipal Health Directorate of East Akim, Eastern Region for their support and cooperation. We thank Dr. Keitum from Kyebi Government Hospital for providing technical support to the team. The authors are also grateful to the study participants for their commitment and responses to the interviews. We acknowledge the support provided by the Traditional Leaders of the various study sites. We are also very thankful to Ms. Racheal Kyerewaa, Ms. Florence Adjomah, Mr. Evans Ankomah, Mr. John Afari and other Community Health Volunteers for their participation in data collection for this study.

\section{References}

1. Mahler H. The Safe Motherhood Initiative: A Call to Action. Lancet. 1987;1:668-70.

2. Gaffey MF, Das JK, Bhutta ZA. Millennium Development Goals 4 and 5: Past and future progress. Semin Fetal Neonatal Med. 2015;20(5):285-92.

3. UNICEF, UNFPA, World Bank Group and the United Nations Population Divisionv. Vol. Trends in Maternal Mortality 2000 to 2017: Estimates by WHO. 2. Washington, D.C: World Bank Group; 2019.

4. Say L, Chou D, Gemmill A, Tunçalp Ö, Moller AB, Daniels J, et al. Global causes of maternal death: A WHO systematic analysis. Lancet Glob Heal. 2014;2(6):323-33. 
5. Kramer MS. The Epidemiology of Adverse Pregnancy Outcomes: An Overview. J Nutr. 2003;133(5):1592S-1596S.

6. Akeju DO, Oladapo OT, Vidler M, Akinmade AA, Sawchuck D, Qureshi R, et al. Determinants of health care seeking behaviour during pregnancy in Ogun State, Nigeria. Reprod Health. 2016;13(1):32; 6774.

7. Factors affecting the utilization of antenatal care Ali SA, Dero AA, Ali SA, Ali GB. Factors affecting the utilization of antenatal care.

8. among pregnant women. A literature review. Journal of Pregnancy Neonatal Medicine. 2018;2(2):415.

9. Gross K, Alba S, Glass TR, Schellenberg JA, Obrist B. Timing of antenatal care for adolescent and adult pregnant women in south-eastern Tanzania. BMC Pregnancy Childbirth. 2012;12:16.

10. Starrs AM. Safe motherhood initiative: 20 years and counting. Lancet. 2006;368(9542):1130-2.

11. WHO Recommendations on Antenatal Care. for a Positive Pregnancy Experience.

12. World Health Organization. 2016;152. ISBN: 9789241549912.

13. Muvandimwe E, Janarthanan V. A study on health care of women during antenatal period. Int J Phys Soc Sci. 2014;4(6):474-83.

14. Babalola S, Fatusi A. Determinants of use of maternal health services in Nigeria - Looking beyond individual and household factors. BMC Pregnancy Childbirth. 2009;9:43.

15. Ghana Statistical Service (GSS), Ghana Health Service (GHS), and ICF. 2018. Ghana.

16. GSS, GHS, and ICF

Accra, Ghana

Maternal HS. 2017. Accra, Ghana: GSS, GHS, and ICF.

17. Tafere TE, Afework MF, Yalew AW. Providers adherence to essential contents of antenatal care services increases birth weight in Bahir Dar City Administration, north West Ethiopia: A prospective follow up study 11 Medical and Health Sciences 1117 Public Health and Health Services 11 Medic. Reprod Health. 2018;15(1):1-8.

18. WHO antenatal care. randomized trial: manual for implementation of the new model. Geneva: World Health Organization; 2002. 37 p. WHO/RHR/01.30.

19. Moller A-B, Petgold M, Chou D, Say L. Early antenatal care visit: a systematic analysis of regional and global levels and trends of coverage from 1990 to 2013.

20. Lancet Glob Health 2017; 5: (10) e977-83.

21. Srivastava A, Mahmood S, Mishra P, Shrotriya V. Correlates of Maternal Health Care Utilization in Rohilkhand Region, India. Ann Med Health Sci Res. 2014;4(3):417-25.

22. Benova L, Tunçalp Ö, Moran AC, Campbell OMR. Not just a number: Examining coverage and content of antenatal care in low-income and middle-income countries. BMJ Glob Heal. 2018;3(2):1-11.

23. Kabir R. Utilization of Antenatal care among pregnant women of Urban Slums of Dhaka City, Bangladesh. IOSR J Nurs Heal Sci. 2013;2(2):15-9. 
24. Ghana Statistical Service. 2010 Population and Housing Census; District Analytical Report. East Akim Municipal. October 2014.

25. Girum T, Wasie A. Correlates of maternal mortality in developing countries: an ecological study in 82 countries. Matern Heal Neonatol Perinatol. 2017;3(1):1-6.

26. Republic of Ghana. National Health Insurance Act (Act 650). 2003;(Act 650):1-2.

27. Ghana Health Service. 2016 Annual Report. Vol. 1. Ghana Health Service; 2017.

28. Asundep NN, Jolly PE, Carson A, Turpin CA, Zhang K, Tameru B. Antenatal care attendance, a surrogate for pregnancy outcome? The case of Kumasi, Ghana. Matern Child Health J. 2014;18(5):1085-94.

29. Olayinka A, Joel A, Bukola D. Factors influencing utilization of antenatal care services among pregnant women in Ife Central Lga, Osun State Nigeria National Hospital Abuja, Nigeria. 2012;3(3):1309-15.

30. Yeji F, Shibanuma A, Oduro A, Debpuur C, Kikuchi K, Owusu-Agei S, et al. Continuum of Care in a Maternal, Newborn and Child Health Program in Ghana: Low Completion Rate and Multiple Obstacle Factors. PLoS One. 2015;10(12):1-23.

31. Ghana Statistical Service (GSS). Ghana Health Service (GHS), ICF International. Ghana Demographic and Health Survey 2014. Maryland: Rockville; 2015.

32. Jalal S, Shah NA. Ante Natal Care (ANC) seeking behavior among women living in an urban squatter settlement: results from an ethnographic study. Italian Journal of Public Health. 2011;8(3):261-7.

33. Muriithi MK. Determinants of Health Seeking Behaviour in a Nairobi Slum. Eur Sci. 2013;9(8):15164.

34. Rahman MM, Rahman MM, Tareque MI, Ferdos J, Jesmin SS. Maternal pregnancy intention and professional antenatal care utilization in Bangladesh: A nationwide population-based survey. PLoS One. 2016;11(6):1-15.

35. Abame DE, Abera M, Tesfay A, Yohannes Y, Ermias D, Markos T, et al. Relationship between unintended pregnancy and antenatal care use during pregnancy in Hadiya Zone, Southern Ethiopia. J Reprod Infertil. 2019;20(1):42-51.

36. Sarker BK, Rahman M, Rahman T, Hossain J, Reichenbach L, Mitra DK. Reasons for preference of home delivery with traditional birth attendants (TBAs) in Rural Bangladesh: A qualitative exploration. PLoS One. 2016;11(1):1-19. 